\title{
Mudanças da PROPAGANdA Eleitoral E EFEITOS NA COMPETIÇÃO E PARTICIPAÇÃO EM ELEIÇÕES MUNICIPAIS BRASILEIRAS ENTRE 2008 E 2016
}

\author{
Emerson U. CERVI* \\ Daniela Silva NEVES ${ }^{* *}$
}

\begin{abstract}
RESUMO: Este trabalho apresenta uma proposta de medição da participação e competição nas eleições brasileiras, utilizando o Índice de Democratização de Tatu Vanhanen, para o qual competição e participação são fundamentais para analisar a democracia em uma eleição. São utilizados dados agregados dos resultados das eleições nos municípios brasileiros entre os anos de 2008 e 2016, associados à estrutura de comunicação tradicional (rádio e TV) e digital nas cidades. A hipótese é a de que existe associação entre intensidade de comunicação e participação eleitoral. O objetivo é analisar se a maior ou menor estrutura de comunicação da propaganda eleitoral afeta a participação e competição das eleições, em um período no qual houve mudanças das leis eleitorais e diminuição do espaço de comunicação tradicional. A pergunta que norteia o trabalho é: a visibilidade das eleições causada com a mudanças nas regras eleitorais diminui a democracia eleitoral nesses municípios? Os resultados mostram que há efeitos em direções contrárias.
\end{abstract}

PALAVRAS-CHAVE: Democracia eleitoral. Eleições locais. Comunicação política. Propaganda eleitoral.

\section{Introdução}

Este artigo propõe-se a analisar a participação e competição nas eleições locais brasileiras a partir da estrutura de comunicação tradicional e digital e das mudanças na legislação sobre propaganda eleitoral. A análise da democracia eleitoral

\footnotetext{
UFPR - Universidade Federal do Paraná. Departamento de Ciência Política. Curitiba - PR - Brasil. ecervi7@gmail.com. https://orcid.org/0000-0001-8073-014X.

* UFPR - Universidade Federal do Paraná. Departamento de Ciência Política. Curitiba - PR - Brasil. dneves1505@gmail.com. https://orcid.org/0000-0002-1334-0085.
} 
é feita através do Índice de Democratização (ID), proposto por Tatu Vanhanen, utilizando as dimensões fundamentais: competição e participação. São analisadas as eleições entre os anos entre 2008 e 2016, utilizando dados agregados dos resultados de votações majoritárias municipais. A estratégia de abordagem mostra que a democracia é composta por diversos indicadores e que estudá-los em forma separada é importante para compreender o sistema como um todo.

A análise de comunicação das campanhas é realizada através da variável estrutura de comunicação eleitoral: tradicional, através do rádio e TV pela transmissão do Horário Gratuito de Propaganda Eleitoral (HGPE); e digital, que é o acesso aos sistemas multimídias em sistema de banda larga. Todos os dados são agregados, portanto, não analisamos o comportamento eleitoral, mas sim os resultados por município. A unidade de análise é o município e não o eleitor.

O trabalho inicia apresentando o resumo da teoria de Tatu Vanhanen (1984, 1990, 1997, 2000, 2003) que resultou no Índice de Democratização, baseado nos indicadores participação e competição eleitoral.

Como são duas dimensões fundamentais para a teoria de Vanhanen e para este trabalho, é importante definir que Vanhanen tem o pressuposto de que quanto maior o nível de participação da população adulta, mais ela está envolvida na disputa pelo poder. E por isso ele utiliza este dado para calcular o indicador de participação. Para a dimensão competição, leva em conta a divisão dos votos dos concorrentes. A concentração de votos em determinado candidato é sinal de baixa democracia eleitoral.

Em seguida, o trabalho descreve como as regras eleitorais, elaboradas pelo Congresso Nacional e pela Justiça Eleitoral a partir da década de 1990, atingem a comunicação política e interferem nas disputas locais. Com isso, mostra como regras eleitorais diretas e indiretas impactam nos processos democráticos e não apenas nas instituições. A comunicação eleitoral tradicional, através do HGPE no rádio e televisão, perdeu espaço em tempo e ao mesmo tempo de importância na campanha. Dessa forma, houve uma redução formal-legal na visibilidade das campanhas nos meios tradicionais (rádio e TV) e aumento das possibilidades por meios digitais.

Por fim, será apresentada a análise de dados para identificar de que forma o índice de democratização das eleições majoritárias locais no Brasil se comportou no período estudado de acordo com a estrutura dos meios de comunicação eleitoral. Para isso, usa como variáveis explicativas indicadores de mudanças nas estruturas de comunicação, eletrônica tradicional (rádio e televisão) e digital (acesso à banda larga) em campanhas locais, em duas eleições: 2008 e 2016. São utilizados os dados agregados do resultado das eleições municipais de primeiro turno em todos os 5.568 municípios, tendo como fonte o Tribunal Superior Eleitoral (TSE). O segundo turno não é considerado por ter apenas dois concorrentes e não ser possível verificar a força dos partidos menores, conforme modelo teórico utilizado. 


\section{Mudanças da propaganda eleitoral e efeitos na competição e participação em eleiçôes municipais brasileiras entre 2008 e 2016}

A pesquisa parte do seguinte problema: como a visibilidade das eleições, consequência das mudanças nas regras eleitorais e mudanças tecnológicas, impacta a democracia eleitoral nesses municípios?

A variável dependente é a Democracia Eleitoral, testada em uma adaptação do Índice de Democratização, de Vanhanen (2003), que indica o grau de democratização eleitoral de cada município em determinada eleição a partir das dimensões "concorrência" e "participação". As variáveis explicativas são comunicacionais. O indicador de comunicação tradicional é a existência ou não de emissoras de rádio no município e a digital é a proporção de acessos à banda larga por número de eleitores nos municípios. As variáveis de controle são: o tamanho do município e pertencer, ou não, a uma região metropolitana.

Com a análise serão testadas as hipóteses: 1) com a mudança nos espaços de comunicação eleitoral, houve redução da participação e da competição eleitoral, ou seja, redução na democracia eleitoral, neste período estudado. 2) Quanto mais estrutura de comunicação tradicional e digital, maior a associação entre as variáveis comunicacionais e o Índice de Democratização. Nossas hipóteses estão no campo da associação entre estrutura de comunicação e democratização e não no campo do determinismo de um sobre o outro.

Em relação à comunicação eletrônica, no período estudado, o Brasil passou por reformas na lei eleitoral, que ao longo do tempo foram reduzindo a presença do HGPE nas campanhas. Houve fracionamento do horário durante a programação, na forma de spots, diminuição do tempo diário de presença dos candidatos (as) no rádio e na televisão e, por fim, redução no número de dias de transmissão do HGPE durante as campanhas. Apenas $14,4 \%$ dos municípios brasileiros possuem canal de TV aberta com programação local, onde moram $52,3 \%$ da população do país (PIERANTI, 2018) e, por isso, em eleições municipais, a grande maioria dos municípios recebe transmissão de horário eleitoral pela TV de outras cidades, ou seja, de candidatos de outros municípios. Da mesma forma, pelos dados coletados na Agência Nacional de Telecomunicações (Anatel) para esta tese, há 1.533 municípios sem nenhuma emissora de rádio ou TV, ou, 27,5\%. Em eleições nas quais há diferença no acesso à comunicação política produzida pelos candidatos é possível medir a variação entre esse e o resultado da eleição, no que se refere à participação e competição. Dado que existe um número significativamente maior de municípios com emissoras de rádio do que de TV e o HGPE tem o mesmo tempo nos dois meios, usaremos aqui cidades com emissoras de rádio para identificar o efeito de HGPE, da comunicação tradicional, sobre a democratização eleitoral. Para a comunicação digital, usamos a proporção de acessos à rede de banda larga em relação ao total de eleitores no município. Os acessos são preditores para maior possibilidade de contato com os conteúdos que circulam em ambientes digitais. 


\section{Participação e competição na teoria de Vanhanen}

Tatu Vanhanen agregou conceitos teóricos consolidados sobre democracia, principalmente a proposta de Robert Dahl (2005), criando um índice capaz de medir os indicadores eleitorais dessas teorias. Há vasta literatura da área que trata de democracia e eleições considerando a importância da participação e competição para o fortalecimento da democracia (ALTMAN, 2002; COPPERDGE e GERRING et al, 2011; LIPJHARDT, 2000, 2007; SCHUDSON, 2008; PRZEWORSKI, ALVAREZ, CHEIBUB e LIMONGI, 2001)

Em comum, o que esses autores/pesquisadores defendem, para além das especificidades de suas pesquisas e objetivos, é que ter eleições livres, frequentes, com ampla participação popular e qualidade na competição, são fatores importantes para se considerar um país democrático. Ou seja, apenas a realização de eleições não garante um regime democrático. A qualidade da eleição é elemento fundamental e por isso alguns autores chamam a atenção para regimes que simulam, controlam ou ainda fraudam as eleições para que essa votação os legitimem a continuar no poder (DIAMOND, 2015; NORRIS, 2015; O'DONNELL, 2001; PRZEWORSKI et al., 2001Referência).

Para Dahl, referência para a proposta de Vanhanen, quanto mais participação (participação ampliada), mais mudança na composição de lideranças políticas eleitas. Quanto mais grupos ou pessoas incluídas na competição, mais os políticos buscam apoio em outros grupos, o que gera mais inclusão na política. Isso, de acordo com Dahl, provoca vários efeitos de longo alcance, como escolher candidatos (as) com perfil mais próximo dos eleitores. "Outra é de se adaptar a retórica, programa, política e ideologia ao que se acredita que sejam os desejos ou interesses dos grupos segmentados ou camadas até então não representados”. (DAHL, 2005, p 43-44).

Para que essas condições se efetivem, é preciso oportunidades iguais, pois se um grupo tem mais oportunidade do que outros para defender seus pontos de vista, suas políticas se perpetuam (DAHL, 2009, p. 50). O autor diz que para satisfazer as exigências de uma democracia, essas garantias precisam ser realmente cumpridas e ter funcionários (governantes) eleitos significa dizer que: "O controle das decisões do governo sobre a política é investido constitucionalmente a funcionários eleitos pelos cidadãos". (DAHL, 2005, p. 99).

Partindo da teoria de Dahl (2005) de que quanto mais participação (participação ampliada), mais mudança na composição de lideranças políticas eleitas, e de que quanto mais grupos incluídos na competição, mais os (as) políticos (as) ${ }^{1}$ buscam apoio em outros grupos, Vanhanen defende que a concorrência (competição) e grau

\footnotetext{
1 Em todas as vezes que a palavra "candidato" ou "político" é apresentado no referencial teórico, por uma decisão dos autores, optou-se por dar a variação do gênero, mesmo que o autor (a) assim não o fez na forma original.
} 


\section{Mudanças da propaganda eleitoral e efeitos na competição e participação em eleiçôes municipais brasileiras entre 2008 e 2016}

de participação (inclusão) aumentariam a divisão dos recursos dentre os diversos grupos. Por isso, para Vanhanen, quanto maior a participação eleitoral, mais forte é a democracia. Da mesma forma, quanto menos concentrado os votos em determinado (a) candidato (a), menor a concentração de poder. Para ele, esses dois indicadores de democratização podem ser usados separadamente para medir o nível de democracia, porém, como eles indicam duas diferentes dimensões da democratização, a combinação dos dois deve trazer resultados mais realísticos (VANHANEN, 2003, p. 63).

Diante essas explicações, surgem os indicadores (VANHANEN, 2000):

Distribuição de poder: (1) a participação percentual dos partidos menores e independentes nos votos emitidos nas eleições parlamentares ou de lugares no parlamento - que indica a concorrência; e (2) a percentagem da população adulta que votou nas eleições - que indica a participação.

Essa distribuição de competição é calculada com a soma de votos recebida pelos partidos com menos votos sendo subtraída da parte do (a) candidato (a) vencedor (a). As duas variáveis foram combinadas em um Índice multiplicando os dois indicadores e dividindo o resultado por $100^{2}$.

$$
I D=\frac{(\text { compID } x \text { partID })}{100}
$$

Onde:

ID = índice de democratização;

compID = indicador de competição;

partID = indicador de participação;

A seleção dos partidos menores e independentes como indicadores da distribuição do poder baseia-se no pressuposto de que, nos estados contemporâneos, os partidos representam importantes centros de poder e que a participação dos partidos menores e independentes mede a distribuição de poder (2003).

Apenas a distribuição de votos e assentos não mede o grau de participação, o envolvimento da população. Por isso, Vanhanen (1997) constrói um índice de distribuição de poder que combina os votos expressos nos partidos menores dos votos no parlamento com o grau de participação. Baseia-se no pressuposto de que quanto maior o nível de participação da população adulta (de acordo com a

\footnotetext{
2 A fórmula é inserida conforme descrito em texto por Vanhanen (2003): "The value of the Competition variable is calculated by subtracting the percentage of votes won by the largest party from $100(\ldots)$ The value of the Participation variable is calculated from the total population, not from the adult or enfranchized population." (p. 56). Desta forma, ele considera o total da população e não só adulta por entender que não existem estatísticas precisas de faixa etária por eleitor em todos os países. No caso brasileiro, como o voto é obrigatório, usaremos o dado "aptos a votar" do TSE.
} 
porcentagem desta apta a votar), mais a população está envolvida na disputa pelo poder.

O nível de participação nas eleições indica uma distribuição de poder entre a população se a participação dos partidos menores também é alta (VANHANEN, 1997), pois, se a porcentagem de votos de pequenos partidos é baixa, a dominância dos maiores partidos é avassaladora (overpowering). Considera competição real se a porcentagem de voto dos partidos de oposição estiver ao menos em 30\%. Abaixo disso, o domínio do maior partido é tão alto que é duvidoso dizer que o país poderia ser considerado como uma democracia (VANHANEN, 2000, p.254).

Por abranger tantos países com sistemas e regras eleitorais diversas, a proposta de Vanhanen foi analisar variáveis mais amplas, porém fundamentais e facilmente encontradas em todas as nações $\mathrm{O}$ índice original foi aplicado para países. Na proposta deste artigo, será aplicado nas mesmas dimensões de Vanhanen competição e participação -, porém em municípios, que obedecem às mesmas regras eleitorais, mas têm estruturas de comunicação diversas.

\section{Comunicação política e desenvolvimento das regras nas eleições brasileiras}

Após a apresentação do Índice de Democratização e discussão teórica da importância dos indicadores de participação e competição para a democracia eleitoral, passa-se a descrever as mudanças na legislação eleitoral que diminuíram o papel da comunicação tradicional (rádio e TV) ao mesmo tempo em que aumentaram a força da comunicação digital.

A legislação eleitoral brasileira modificada em 2015 restringiu a divisão de tempo de horário eleitoral gratuito entre os partidos e ainda diminuiu o tempo de campanha e período de HGPE. Tal divisão era mais equilibrada, chegando a ser, em 1992, dividida igualitariamente entre os partidos com representação no Congresso Nacional e Assembleia Legislativa. Da mesma forma, o tempo de campanha foi, em 1992, de 70 dias, passando para 122 nas eleições seguintes, chegando a 45 dias no pleito de 2016.

Entre os pleitos analisados, as restrições para a propaganda eleitoral aumentaram, principalmente a de rua. Em 1996 eram permitidas faixas, placas, cartazes, pinturas ou inscrições, ou murais de qualquer dimensão, distribuição de folhetos, e a propaganda utilitária - como bonés, canetas, réguas e camisetas (BRASIL, 1995). Dez anos depois, a campanha de rua praticamente desaparece. Ao mesmo tempo, a legislação se adaptou ao advento das novas tecnologias e mídias sociais, inserindo restrições e permissões para os meios digitais (BRASIL, 2009; BRASIL, 2015; CAMPELO, 2017; NEVES e SANTOS, 2017). 


\section{Mudanças da propaganda eleitoral e efeitos na competição e participação em eleiçôes municipais brasileiras entre 2008 e 2016}

No quadro 1 mostra que a legislação de 1991, que normatizou as eleições de 1992, era simples, declarando de forma genérica permissões e proibições em propaganda de rua em locais públicos e particulares. As normas seguintes foram agregando temas de propaganda eleitoral.

A reforma de 2015 restringe a propaganda de rua, flexibilizando um pouco a propaganda de TV, permitindo gravações externas em determinadas situações explicitadas. Sobre as regras de Divisão do Tempo de Propaganda, o modelo brasileiro leva em consideração a força relativa dos partidos e divide o tempo de propaganda proporcionalmente à representação de cada um deles na Câmara dos Deputados. As eleições de 1996 são as com tempo de propaganda no rádio e TV mais abrangente (60 dias), com queda nos anos posteriores e diminuição maior no último pleito (35 dias). Neste mesmo período, também houve mudança nas regras de tempo diário de HGPE em bloco e distribuição do tempo entre as coligações:

Quadro 1 - reformas na legislação eleitoral sobre propaganda entre 1991 e 2016

\begin{tabular}{|l|c|c|c|c|c|c|c|c|}
\hline \multicolumn{1}{|c|}{ Legislação } & $\begin{array}{c}\text { Lei } \\
\mathbf{8 2 1 4 / 9 1}\end{array}$ & $\begin{array}{c}\mathbf{8 7 1 3 / 1 9 9 3} \\
\mathbf{9 1 0 0 / 9 5}\end{array}$ & $\begin{array}{c}\text { Lei } \\
\mathbf{9 5 0 4 / 9 7}\end{array}$ & $\begin{array}{c}\text { Lei } \\
\mathbf{1 1 3 0 0 / 2 0 0 6}\end{array}$ & $\begin{array}{c}\text { Lei } \\
\mathbf{1 2 0 3 4 / 2 0 0 9}\end{array}$ & $\begin{array}{c}\text { Lei } \\
\mathbf{1 2 8 9 1 / 2 0 1 3}\end{array}$ & $\begin{array}{c}\text { Lei } \\
\mathbf{1 3 1 6 5 / 2 0 1 5}\end{array}$ \\
\hline Aplicada em & 1992 & 1994 & 1996 & $\begin{array}{c}1998 \mathrm{e} \\
\text { posteriores }\end{array}$ & $\begin{array}{c}2006 \mathrm{e} \\
2008\end{array}$ & $2010 \mathrm{e} 2012$ & 2014 & 2016 \\
\hline $\begin{array}{l}\text { Período de } \\
\text { propaganda } \\
\text { eleitoral (dias) }\end{array}$ & 70 & $\begin{array}{c}\text { De } 151 \mathrm{a} \\
123\end{array}$ & 122 & 86 & 87 & 87 & 45 & 45 \\
\hline $\begin{array}{l}\text { Período de } \\
\text { HGPE (dias) }\end{array}$ & 45 & 60 & 60 & 45 & 45 & 45 & 45 & 35 \\
\hline $\begin{array}{l}\text { Tempo diário } \\
\text { (minutos) }\end{array}$ & 80 em 2 & 120 & $\begin{array}{c}90 \text { em 3 } \\
\text { blocos }\end{array}$ & $\begin{array}{c}100 \text { eleições } \\
\text { gerais/ } 60 \\
\text { municipais }\end{array}$ & $\begin{array}{c}60 \text { em } 2 \\
\text { blocos }\end{array}$ & $\begin{array}{c}60 \text { em } 2 \\
\text { blocos }\end{array}$ & $\begin{array}{c}60 \text { em } 2 \\
\text { blocos }\end{array}$ & $\begin{array}{c}20 \text { em } 2 \\
\text { blocos }\end{array}$ \\
\hline $\begin{array}{l}\text { Distribuição } \\
\text { igualitária }\end{array}$ & $25 \%$ & $4,70 \%$ & $20 \%$ & $33,30 \%$ & $33,30 \%$ & $33,30 \%$ & $33,30 \%$ & $10 \%$ \\
\hline $\begin{array}{l}\text { Distribuição } \\
\text { entre partidos* }\end{array}$ & $75 \%$ & $58,30 \%$ & $80 \%$ & $66,70 \%$ & $66,70 \%$ & $66,70 \%$ & $66,70 \%$ & $90 \%$ \\
\hline
\end{tabular}

*Com representantes eleitos na Câmara dos Deputados.

Fonte: Leis eleitorais (BRASIL, 2017, 1997).

Mesmo com uma divisão mais complexa, em 1992 respeitava a representatividade entre os partidos no Poder Legislativo, estadual e federal. De 1996 a 2012, permaneceu a mesma, fixando a representação na Câmara Federal como critério. A legislação de 2015 prevê que $90 \%$ do tempo são distribuídos proporcionalmente ao número de representantes na Câmara dos Deputados, e 10\% distribuídos igualitariamente. 
Sobre o ambiente virtual, a possibilidade de propaganda digital surge em 2000, ainda não na Lei Eleitoral propriamente dita, mas através de resolução $-\mathrm{n}^{\circ}$ 20.684 -, que especificava o uso do domínio online de registro de sites de candidatos (as), nas eleições municipais daquele ano. Seguida pela Resolução n ${ }^{\circ} 20.988$ em 2002, que impõe para a propaganda através da internet, as mesmas permissões e normas da propaganda em geral, como período, proibição de propaganda antecipada, normas para transmissão de debates e realização ou divulgação de consultas populares.

Nas eleições de 2006 a palavra internet surge na Lei 11.300300 (BRASIL, 2006). Em seu $\S 4 .^{\circ}$, indica que as prestações de campanha devem ser realizadas pelos partidos políticos, coligações e os candidatos (as) através da rede mundial de computadores, nos dias 6 de agosto e 6 de setembro, "em sítio criado pela Justiça Eleitoral para esse fim, exigindo-se a indicação dos nomes dos doadores e os respectivos valores doados somente na prestação de contas final de que tratam os incisos III e IV do art. 29 desta Lei.”. É a única menção à rede. Até as eleições de 2010, a propaganda on-line era restrita a sites oficiais de candidaturas, ou partidos. A partir de 2009 com a Lei 12.034 (BRASIL, 2009) o tema internet toma corpo na legislação.

Apenas após 2009, a legislação eleitoral permitiu que as campanhas explorarem a campanha digital. Em 2010 ocorre a permissão de propaganda através de blogs, redes sociais e aplicativos de mensagens. Considerando que o Facebook foi criado em 2004, e as plataformas Youtube e Twitter em 2006, essa adaptação para os formatos digitais poderia ter ocorrido antes.

Com a ampliação do uso, nesta mesma Lei № 12.034 é prevista a livre manifestação de opinião dos internautas, desde que não seja de forma anônima. A propaganda negativa é potencializada com a campanha on-line, ainda mais com a permissão de manifestação de internautas. Por isso, além da proibição do anonimato, é acrescentado o direito de resposta.

A Lei 12.891/2013 (BRASIL, 2013) intensifica o combate à propaganda negativa, obrigando a retirada - não apenas o direito de resposta - do conteúdo ofensivo, bem como a contratação direta ou indireta de grupo de pessoas com a finalidade específica de emitir mensagens ou comentários na internet para ofender a honra ou denegrir a imagem de candidato, partido ou coligação - deixando explicita uma prática dos comitês de campanha.

A mudança advinda da Lei 13.165/2015 (BRASIL, 2015) amplia as possibilidades de uso, flexibilizando a divulgação de candidatura antes do período de propaganda oficial. Desta forma, não considera propaganda antecipada na internet a menção à pretensa candidatura, a exaltação das qualidades pessoais dos pré-candidatos (as), desde que não haja pedido explícito de voto. 


\section{Mudanças da propaganda eleitoral e efeitos na competição e participação em eleiçôes municipais brasileiras entre 2008 e 2016}

As normativas sobre propaganda eleitoral digital demoraram a aparecer expressamente na lei e foram sendo aprimoradas em função do uso das redes por parte dos brasileiros. De acordo com dados da Pesquisa Brasileira de Mídia (BRASIL, 2016), promovida pelo Governo Federal, 2/3 da população brasileira acessava internet e o telefone celular é o grande responsável pela expansão do uso da rede no país $-72 \%$ dos que acessavam a internet usavam como principal meio o celular. Em apenas um ano a expansão foi expressiva, visto que na edição anterior da pesquisa (2015), a porcentagem de usuários era próxima da metade (48\%).

Através de mudanças na legislação, a partir das eleições de 2010 as campanhas passam a ter possibilidades de maior interação com os eleitores pela Web, através das redes sociais. Entram nesta operação especialistas em marketing digital, profissionais especialistas em fazer com que seu cliente alcance mais pessoas em redes sociais como o Facebook. A legislação de 2017 abriu a possibilidade de impulsionamento para a campanha de 2018, o que permite ultrapassar a barreira do algoritmo através de impulsionamento pago de posts em mídias sociais. Quando se impulsiona uma publicação, é possível alcançar o público alvo dela, chegando a filtros de idade e bairros onde mora, por exemplo. Até a campanha de 2016, essa prática era punida. Como este artigo tem um recorte temporal até 2016, não analisará a possiblidade de impulsionamento.

A descrição das mudanças nas regras mostra que a legislação veio restringindo a forma tradicional de campanha, ao mesmo tempo que abre maiores possibilidades de comunicação eleitoral digital. Além disso, traz uma mudança importante, que é a perda do controle total da comunicação eleitoral pelos comitês, candidatos (as) e partidos, ou seja, a elite política (CERVI; NEVES, 2018). Após esta descrição, analisaremos como as mudanças na legislação estão associadas à participação e competição nas eleições municipais brasileiras.

\section{Índice de democratização aplicado para eleições majoritárias brasileiras}

A análise a partir daqui pretende testar as hipóteses: 1) com a mudança nos espaços de comunicação eleitoral, houve redução da participação e da competição eleitoral, ou seja, redução na democracia eleitoral, neste período estudado. 2) Quanto mais estrutura de comunicação tradicional e digital, maior a associação entre as variáveis comunicacionais e o Índice de Democratização.

A variável dependente é a democracia eleitoral, testada em uma adaptação do Índice de Democratização, de Vanhanen, feita por Cervi (2017, p. 6-7), que utilizou o índice para calcular o caso brasileiro no resultado das eleições nos municípios de 2016, majoritária e proporcional. As variáveis explicativas são comunicacionais - 
tradicionais (emissoras de rádio e TV), que indicam a presença de horário eleitoral nas eleições locais, e digital (Serviço de Comunicação de Multimídia), que indica maior velocidade e capacidade de acesso aos conteúdos pela web.

Os dados estão disponíveis no site do Tribunal Superior Eleitoral (Repositório do TSE), com detalhe da votação por município e zona e votação no (a) candidato (a) por município e zona eleitoral. Para identificar a estrutura de acesso à internet no município foi utilizada a média de pontos de acessos a SCM (Serviço de Comunicação de Multimídia) registrados na Anatel (Agência Nacional de Telecomunicações) no período analisado.

Foram calculados os índices tendo como base o resultado do primeiro turno das eleições, visto que é nele que se dá a concorrência de fato entre o candidato ganhador e os demais concorrentes, conforme a premissa de Vanhanen (2003, p.57) ao definir que, para haver competição, é preciso verificar o espaço de disputa dos pequenos partidos.

Vanhanen (2000) considera o total de população, e não somente adultos, para calcular a participação por entender que há mais dados sobre população total do que adultos eleitores em todos os países pesquisados. Utilizou dados comuns em todos os países estudados. Temos uma vantagem no Brasil quanto à precisão de dados: como no país o voto é obrigatório, o dado "aptos a votar" do TSE nos dá com segurança o retrato de cada município quanto à quantidade de pessoas que podem votar. E por isso a fórmula de Vanhanen foi adaptada.

Desta forma, os indicadores foram calculados com as seguintes fórmulas:

$$
\text { CompID }=\frac{(\text { compar }- \text { vot melhorcolocado })}{\text { Compar }-1} \times 100
$$

Onde:

CompID: indicador de competição

Compar: comparecimento nas eleições

Vot_melhorcolocado: quantidade de votos recebida pelo candidato (a) que ficou em primeiro lugar, com dados do primeiro turno.

A divisão de comparecimento -1 é porque, estatisticamente, só é significativo quando há variação do valor. Considera-se o comparecimento o total de votos nominais, brancos, nulos, ou seja, o total de pessoas que votaram de alguma forma nas eleições majoritárias. A variável voto no melhor colocado considera o total de votos recebidos pelo candidato que recebeu o maior número de votos no primeiro turno, mesmo que a disputa siga para o segundo turno e independentemente do número de votos recebidos pelo segundo colocado. Para calcular o indicador de participação, foi usada a fórmula adaptada por Cervi (2017): 
Mudanças da propaganda eleitoral e efeitos na competição e

participação em eleiçôes municipais brasileiras entre 2008 e 2016

$$
\text { PartID }=\frac{\text { Compar }}{\text { Eleitores_aptos }} X 100
$$

Onde:

PartID: indicador de participação

Eleitores_aptos: inscritos na Justiça Eleitoral que estão aptos a votar naquele ano

Com os dois indicadores, foram calculados os Índice de Democratização com a fórmula original de Vanhanen (2003):

$$
I D=\frac{(\operatorname{CompIDX} \text { PartID })}{100}
$$

Dados obtidos através do Repositório do Tribunal Superior Eleitoral (TSE):

a) Dados agregados de resultado de eleições municipais contendo o Nome do Município com o código do TSE para ele e o código do IBGE para o mesmo. Os códigos permitem comparar dados de municípios que mudaram de nome.

b) Total de votos no (a) eleito (a) naquele município. Quando a cidade apresentou segundo turno, o dado utilizado é da quantidade de votos recebidos pelo (a) eleito (a), porém no primeiro turno para medir a concentração de voto recebida entre este (a) e os (as) demais concorrentes.

c) Total de eleitores aptos a votar naquele município e ano;

d) Comparecimento na votação.

e) Abstenção: total de aptos, menos os que votaram.

f) Voto nominal: que foi para um (a) dos (as) candidatos (as);

g) Voto em Branco;

h) Voto Nulo.

Tendo o ID, PartID e CompID, é possível calcular a regressão linear com as variáveis comunicacionais. A regressão linear permite identificar determinações, ou seja, quanto que, ao aumentar uma unidade na variável explicativa, é possível predizer de aumento na variável dependente (CERVI, 2017). O Beta é acompanhado do grau de significância, considerado estatisticamente significativo o resultado que demonstrar significância abaixo de 0,050 . A estatística t é outro indicador de validade 
da relação testada: quanto maior for o valor $\mathrm{t}$ ( $t$ value), maior será a associação de uma variável sobre outra. Para as regressões lineares múltiplas, são utilizados os seguintes dados fornecidos pela Anatel:

a) Quantidade de rádio FM no Município;

b) Quantidade de rádio FM Educativa no Município;

c) Quantidade de emissoras de TV com sinal analógico;

d) Quantidade de emissoras de TV educativas;

e) Quantidade de emissoras de rádio comunitárias;

f) Ondas curtas na cidade;

g) Ondas médias na cidade;

h) A soma de todos esses itens fornece a quantidade total. Esse é o dado utilizado na regressão.

i) SCM médio do município: quantidade de acessos à rede de Comunicação Multimídia dividido pelo número de eleitores.

Para o indicador utilizado nesta pesquisa, o banco de dados não apresenta a quantidade e sim presença ou ausência de emissoras nos municípios.

A tabela a seguir mostra os números totais de emissoras e estrutura de Comunicação Multimídia dos anos de 2012 e 2016.

Tabela 1 - estatísticas descritivas das variáveis independentes

\begin{tabular}{l|c|c|c|l|c|c|c}
\hline Estatística & RADTV_12 & RADTV_16 & DIF1612 & Estatística & SCM08 & SCM16 & DIFSCM1608 \\
\hline Munic. & 4.038 & 4.239 & 201 & Média & 0,017 & 0,066 & 0,049 \\
\hline Total & 8.905 & 9.680 & 775 & Desv. Pad. & 0,028 & 0,074 & 0,055 \\
\hline
\end{tabular}

Fonte: CERVI; NEVES, 2018. Para número de emissoras de rádio e TV: http://sistema.mc.gov.br/DSCOM/view/ Informacoes.php

Fonte para SCM: http://www.anatel.gov.br/dados/. Acessos em 28/5/2018

Na tabela 1, RADTV: Quantidade de emissoras em 2012 (RADTV_12) e 2016 (RADTV_16).DIF1612: a diferença nominal entre os dos anos. SCM: Sistema de Comunicação Multimídia (acessos) divididos pelo número de eleitores em 2008 (SCM08) e 2016 (SCM16). DIFSCM1608: diferença entre os dois anos resultante dessa divisão. De forma sumarizada, foram utilizados os seguintes dados para as variáveis independentes: 
Mudanças da propaganda eleitoral e efeitos na competição e participação em eleiçôes municipais brasileiras entre 2008 e 2016

Quadro 2 - dados utilizados para as variáveis independentes

\begin{tabular}{|l|l|}
\hline \multicolumn{1}{|c|}{ VARIÁVEIS INDEPENDENTES } & \multicolumn{1}{c|}{ DADOS UTILIZADOS } \\
\hline Comunicação tradicional: Rádio e TV & $\begin{array}{l}\text { Variável Dummy - presença ou ausência de } \\
\text { emissoras de rádio e TV. }\end{array}$ \\
\hline Comunicação digital & $\begin{array}{l}\text { Sistema de Comunicação Multimídia (SCM) médio } \\
\text { do município: quantidade de acessos à rede de } \\
\text { Comunicação Multimídia dividido pelo número de } \\
\text { eleitores. }\end{array}$ \\
\hline
\end{tabular}

Fonte: os autores

Sobre o acesso à internet (SCM), a média anual de pontos de acesso foi dividida pelo número de eleitores registrados no município por ano eleitoral. $\mathrm{O}$ resultado é a proporção de acessos à internet fixa por eleitor em cada um dos 5,6 mil municípios brasileiros (CERVI; NEVES, 2018). Como a Anatel possui dados de emissoras de rádio e televisão para todos os municípios brasileiros a partir de 2012, é utilizado esse ano como base para as análises relativas à eleição de 2008. Sobre a presença de emissoras nos municípios brasileiros, duas informações chamam atenção na tabela: em 2012 havia 8.905 emissoras de rádio e televisão no Brasil, distribuídas em 4.038 municípios. Em 2016 o número sobe para 9.680 emissoras, em 4.239, o que indica um crescimento de $4,7 \%$ de municípios com emissoras próprias no último ano em relação ao primeiro (CERVI; NEVES, 2018). Emissoras próprias são as localizadas no município que transmitem programação. Em cidades onde não há, moradores recebem programação transmitida de outras cidades, inclusive o horário eleitoral dos candidatos (as) da cidade sede da emissora.

A variável explicativa que indica acessos à internet também apresentou crescimento no período. A média da proporção de SCM por eleitor foi de 0,017 em 2008, o que significa $1,7 \%$ de eleitores em média de acessos à internet fixa por município. Enquanto em 2008, no Brasil, havia 80 municípios sem SCM para internet fixa, em 2016 esse número caiu para apenas quatro municípios sem o serviço [Presidente Juscelino (RN), Lago de Itaenga (PE), Seridó (PB) e Curuá (PA)] (CERVI; NEVES, 2018).

A segunda variável explicativa é dicotômica, indicando se o município tem ou não tem pelo menos uma emissora de rádio ou televisão no ano eleitoral. Os dados apresentaram o seguinte resultado para os anos estudados, inicia-se pelo Índice de Democratização 2008 associado (por regressão linear) com dados sobre comunicação tradicional e digital: 
Tabela 2: modelo para índice de democratização - 2008

\begin{tabular}{l|r|r|r|r}
\multicolumn{1}{c|}{ Variáveis } & Coef. B. & Desvio padrão & \multicolumn{1}{c|}{ Estat. t } & \multicolumn{1}{c}{ Sig. } \\
\hline (Intercepto) & 42.85 & 0.21 & 199.21 & $0,00 * * *$ \\
\hline Comunicação Digital (C_Digital) & 3.16 & 4.06 & 0.77 & 0.43 \\
\hline Comunicação Tradicional (C_Tradic) & 0.28 & 0.25 & 1.09 & 0.27 \\
\hline
\end{tabular}

Fonte: os autores

De acordo com o modelo, cada ponto a mais de comunicação digital faz com que o ID aumente em 3,16 vezes e para cada emissora de rádio, aumenta em 0,28 . O resultado, tanto para mídia tradicional (C_Tradicional) quanto para digital (C_Digital) não são estatisticamente significantes ${ }^{3}$. Os indicadores de competição e participação foram separados para a realização de novos testes:

Tabela 3: modelos para indicadores separados - 2008

\begin{tabular}{l|r|r|r|r|r|r|r|c}
\hline \multirow{2}{*}{ Variáveis } & \multicolumn{4}{|c|}{ ID_Part2008 } & \multicolumn{4}{c}{ ID_Comp 2008 } \\
\cline { 2 - 9 } & Coef. B & Desv.pad & Estat. t & \multicolumn{1}{c|}{ Sig. } & Coef. B & Desv.pad & Estat. t & Sig. \\
\hline Intercepto & 90.34 & 0.13 & 661.57 & $\begin{array}{r}0,00 \\
* * *\end{array}$ & 47.51 & 0.24 & 196.26 & $0,00 * * *$ \\
\hline C_Digital & -11.68 & 2.58 & -4.52 & $\begin{array}{r}0,00 \\
* * *\end{array}$ & 9.98 & 4.57 & 2.18 & $0.00113 * *$ \\
\hline C_Tradic & -2.34 & 0.16 & -14.26 & $\begin{array}{r}0.00 \\
* * *\end{array}$ & 1.57 & 0.29 & 5.41 & $0.00 * * *$ \\
\hline
\end{tabular}

Fonte: os autores

Os resultados para cada um dos componentes (participação e competição) mostram que quanto mais comunicação, menos participação. A comunicação digital gera uma associação negativa de $(-11,68)$. Já para a competição eleitoral os efeitos são positivos em todos os casos, porém menos significativos para comunicação digital.

A diferença é negativa para o componente participação tanto em emissoras de rádio e TV quanto acesso à internet. Assim, nos municípios em que houve presença de emissoras de rádio e TV e maior crescimento na proporção de acessos à internet por eleitor, houve menos participação eleitoral. Já em relação à competição, em municípios com emissoras de rádio e TV e com mais acesso à internet a competição eleitoral também cresce. A diferença é mais significativa para as variações de

3 Foram realizados testes de colinearidade entre as variáveis explicativas do modelo e para todos os anos testados o o VIF (Variance Inflating Factor) deu abaixo de 4 (CERVI, 2019), o que não aponta correlação cruzada. 
presença dos meios eletrônicos tradicionais do que para acessos à comunicação digital.

Agora, comparando com os dados de 2012, no ID geral, a comunicação digital tem mais força para aumento do índice:

Tabela 4: Índice de Democratização com variáveis comunicacionais 2012

\begin{tabular}{l|c|c|c|c}
\multicolumn{1}{c|}{ Variáveis } & Coef. B & Desvio padrão & Estat. t & Sig. \\
\hline (Intercepto) & 13.75 & 8.13 & 1.69 & 0,09 \\
\hline C_Digital & 84.96 & 80.64 & 1.05 & 0.29 \\
\hline C_Tradicional & -29.84 & 9.60 & -3.1 & $0.001^{* *}$ \\
\hline
\end{tabular}

Fonte: os autores

Da mesma forma que para os dados de 2008, em 2012 a comunicação digital não é significativa para explicar o Índice de Democratização. A partir desse resultado, os componentes foram separados no teste para verificar se apresentam o mesmo comportamento de 2008, com maior explicação:

Tabela 5: indicadores de participação e competição em 2012

\begin{tabular}{l|r|r|r|r|r|r|r|r}
\hline \multirow{2}{*}{ Variáveis } & \multicolumn{4}{|c|}{ ID_Part2008 } & \multicolumn{4}{c}{ ID_Comp 2008 } \\
\cline { 2 - 9 } & Coef. B & Desv.pad & Estat. t & \multicolumn{1}{c|}{ Sig. } & Coef. B & Desv.pad & \multicolumn{1}{c}{ Estat. t } & Sig. \\
\hline Intercepto & 103.26 & 4.17 & 24.75 & $0,00 * * *$ & 55.83 & 5.66 & 9.85 & $0,00 * * *$ \\
\hline C_Digital & -98.87 & 41.38 & -2.38 & $0.01 *$ & -830.14 & 56.26 & -14.75 & $0,00 * * *$ \\
\hline C_Tradic. & -35.74 & -4.92 & -7.25 & $0,00 * * *$ & -2.41 & 6.69 & -0.36 & 0.71 \\
\hline
\end{tabular}

Fonte: os autores

No componente participação, comunicação digital é pouco significativo e as duas variáveis diminuem a participação, porém a comunicação tradicional apresenta resultado significativo. Em competição, quanto mais comunicação digital menos competição e a comunicação tradicional não é significativa neste modelo.

O resultado é diferente de 2008. Apesar de também ser mais explicativo do que associar apenas com o índice geral, neste caso a inferência da regressão entre comunicação digital e participação não pode ser levada em consideração, da mesma forma como o indicador de competição e a comunicação tradicional não apresenta uma associação com significância estatística, ou seja, o horário eleitoral não fez diferença na competição em 2012. Por último, foram feitos os testes para o resultado de 2016. 
Tabela 6: ID 2016 controlado por variáveis comunicacionais

\begin{tabular}{l|r|r|r|c}
\hline \multicolumn{1}{c|}{ Variáveis } & \multicolumn{1}{c|}{ Coef. B } & \multicolumn{1}{c|}{ Desvio padrão } & \multicolumn{1}{c|}{ Estat. t } & \multicolumn{1}{c}{ Sig. } \\
\hline (Intercepto) & 41.44 & 0.23 & 178.34 & $0,00 * * *$ \\
\hline C_Digital & 10.93 & 1.50 & 7.26 & $0,00 * * *$ \\
\hline C_Tradicional & 0.35 & 0.26 & 1.34 & $0.0179 *$ \\
\hline
\end{tabular}

Fonte: os autores

Os componentes foram separados para comparação com o modelo aplicado aos anos anteriormente estudados. Para o ID geral de 2016, a comunicação digital é significante, mas a tradicional não. Ou seja, novamente leva a crer que o Índice de Democratização deve ser separado em seus indicadores. Antes, também foram aplicados os mesmos controles para os anos anteriores, de localização do município e tamanho.

Tabela 7: indicadores 2016 com variáveis comunicacionais

\begin{tabular}{l|r|r|r|r|r|r|r|r}
\hline \multirow{2}{*}{ Variáveis } & \multicolumn{4}{|c|}{ ID_Part2008 } & \multicolumn{4}{c}{ ID_Comp 2008 } \\
\cline { 2 - 9 } & Coef. B & Desv.pad & & Coef. B & Desv.pad & & Coef. B & Desv.pad \\
\hline Intercepto & 88.19 & 0.16 & 545.87 & $0.00^{* * *}$ & 46.97 & 0.26 & 174.38 & $0.00 * * *$ \\
\hline C_Digital & -10.37 & 1.04 & -9.91 & $0.00^{* * *}$ & 19.73 & 1.74 & 11.30 & $0.00^{* * *}$ \\
\hline C_Tradic. & -2.38 & 0.18 & -12.97 & $0.00^{* * *}$ & 1.76 & 0.30 & 5.75 & $0.00 * * *$ \\
\hline
\end{tabular}

Fonte: os autores

O resultado de 2016 tem semelhança com 2008. As variáveis são estatisticamente significativas e ter mais acesso à comunicação digital ou presença da tradicional diminui a participação. A variável de competição tem nos dois componentes comunicacionais significância estatística e mesma direção, ou seja, ter emissoras de rádio e mais acesso à banda larga ajudou, em 2016, a aumentar a competição eleitoral entre as candidaturas. A comparação do resultado dos coeficientes para as três eleições municipais é: 
Mudanças da propaganda eleitoral e efeitos na competição e participação em eleiçôes municipais brasileiras entre 2008 e 2016

Tabela 8: resultado de coeficientes dos três anos estudados

\begin{tabular}{|c|c|c|c|c|c|c|}
\hline \multirow[b]{2}{*}{ ANO } & \multicolumn{6}{|c|}{ VARIÁVEIS } \\
\hline & $\begin{array}{l}\text { ID E C } \\
\text { DIGITAL }\end{array}$ & $\begin{array}{l}\text { ID E C } \\
\text { TRADIC }\end{array}$ & $\begin{array}{l}\text { ID_PART E } \\
\text { C_DIGITAL }\end{array}$ & $\begin{array}{l}\text { ID_PART E } \\
\text { C_TRADIC. }\end{array}$ & $\begin{array}{l}\text { ID_COMP E } \\
\text { C_DIGITAL }\end{array}$ & $\begin{array}{l}\text { ID_COMP E } \\
\text { C_TRADIC }\end{array}$ \\
\hline 2008 & 3.16 & 0.28 & $-11.68 * * *$ & $-2.34 * * *$ & $9.98 * * *$ & $1.57 * * *$ \\
\hline 2012 & 84.96 & $-29,84$ & $-98.97 *$ & $-35.74 * * *$ & $-830.14 * * *$ & -2.41 \\
\hline 2016 & $10.93 * * *$ & 0.35 & $-10.37 * *$ & $-2.38^{* *}$ & $19.73 * *$ & $1.76^{* *}$ \\
\hline
\end{tabular}

Fonte: os autores

Em 2016 a associação entre ID e comunicação digital tem resultado significativo, mas não com comunicação tradicional. Em 2016, ter mais acesos à banda larga ajudou o índice geral, o que muda o comportamento das eleições anteriores analisadas.

A participação associada à comunicação digital tem significância estatística maior em 2008, porém em sentido contrário: o ID geral diminui com o aumento do acesso à banda larga no município. Com a comunicação tradicional, também estão em sentido contrário, tendo o horário eleitoral associação negativa com a participação, tanto em 2008 quanto em 2012. Da mesma forma em 2016, mas menos intensamente.

A separação dos indicadores mostra não somente que os testes apresentam resultados significativos como a diferença de direção das associações feitas. De forma resumida, temos o seguinte comportamento para os três anos estudados, no quadro 3 a seguir. 
Quadro 3 - resumo dos testes de regressão linear para os anos estudados

\begin{tabular}{|c|c|c|c|c|c|c|c|}
\hline \multirow{2}{*}{ Ano } & \multirow{2}{*}{ Variável } & \multicolumn{2}{|c|}{ Índice Geral } & \multicolumn{2}{|c|}{ Participação } & \multicolumn{2}{|c|}{ Competição } \\
\hline & & Significativo & Direção & Significativo & Direção & Significativo & Direção \\
\hline \multirow{4}{*}{2008} & C_Dig & Não & & $\operatorname{Sim} * * *$ & Contrária - & $\operatorname{Sim} * *$ & Mesma + \\
\hline & C_Trad & Não & & $\mathrm{Sim}^{* * *}$ & Contrária - & $\mathrm{Sim}^{* * *}$ & Mesma + \\
\hline & $\mathrm{RM}$ & $\operatorname{Sim}^{* * *}$ & Mesma+ & $\operatorname{Sim}^{* * *}$ & Mesma + & Não & \\
\hline & Tamanho & Sim*** & Mesma + & Sim*** & Contrária - & $\operatorname{Sim} * * *$ & Mesma + \\
\hline \multirow{4}{*}{2012} & C_Dig & Não & & Sim* & Contrária - & $\operatorname{Sim}^{* * *}$ & Contrária - \\
\hline & C_Trad & Não & & $\operatorname{Sim}^{* * *}$ & Contrária - & Não & \\
\hline & $\mathrm{RM}$ & Sim** & Mesma + & $\operatorname{Sim} * * *$ & Mesma + & Sim** & Mesma + \\
\hline & Tamanho & $\operatorname{Sim} * * *$ & Contrária- & $\operatorname{Sim}^{* * *}$ & Contrária - & Não & \\
\hline \multirow{4}{*}{2016} & C_Dig & $\operatorname{Sim}^{* * *}$ & Mesma + & $\operatorname{Sim}^{* *}$ & Contrária - & Sim** & Mesma + \\
\hline & C_Trad. & Não & & $\operatorname{Sim} * *$ & Contrária - & $\operatorname{Sim}^{* *}$ & Mesma + \\
\hline & RM. & $\operatorname{Sim}^{* * *}$ & Mesma + & $\operatorname{Sim} * * *$ & Mesma + & $\operatorname{Sim} * * *$ & Mesma + \\
\hline & Tamanho & Sim*** & Mesma + & $\operatorname{Sim} * * *$ & Contrária - & $\operatorname{Sim}^{* * *}$ & Contrária - \\
\hline \multicolumn{8}{|c|}{$\begin{array}{l}\text { Notas: } \\
\text { Intercepto: (ou coeficiente linear) ponto em que a reta cruza o eixo Y quando o valor de X é zero. } \\
\text { C_Dig: Comunicação digital - acessos por eleitor } \\
\text { C_Trad: Comunicação Tradicional - emissoras de rádio e TV } \\
\text { T Value: coeficiente "t". Indica a precisão do modelo. Quanto mais longe de zero, mais precisa } \\
\text { será a predição do modelo quanto à associação entre X e Y. Quanto mais asteriscos, maior o nível } \\
\text { de confiança do resultado. } \\
\text { RM- Se o município faz parte de uma região metropolitana } \\
\text { Tamanho - Tamanho do município de acordo com a classificação do TSE, de seis tamanhos de } \\
\text { acordo com número de eleitores. }\end{array}$} \\
\hline
\end{tabular}

Fonte: os autores

Levando em consideração os testes que tiveram resultado significativo, é melhor analisar os indicadores em separado, já que o Índice de Democratização (ID) geral não apresenta resultados significativos. Para os dados analisados, calcular apenas o índice geral não explica as diferenças de maior ou menor democracia eleitoral. Os dados municipais controlados pelas variáveis comunicacionais ajudam a compreender a diferença entre os índices, de acordo com o acesso maior ou menor à estrutura de rádio, TV ou comunicação digital, o que confirma que é preciso separar os indicadores de participação e concorrência.

Nos modelos de regressão com resultado de significância estatística, o maior acesso à Comunicação Digital impacta negativamente o indicador de participação em 2008 (-11.68), 2012 (-98.97) e 2016 (-10.37). A Comunicação Tradicional 


\section{Mudanças da propaganda eleitoral e efeitos na competição e participação em eleiçôes municipais brasileiras entre 2008 e 2016}

também reduz a participação nos três anos estudados - sendo -2.34 em 2008, -35.74 em 2012 e -2.38 em 2016. Ou seja, quanto mais emissoras tem o município, menos participação na votação.

Quando testado o componente competição, as duas variáveis comunicacionais indicam aumento da competição em 2008 e 2016, mas não em 2012. No primeiro ano testado, a associação com a comunicação tradicional apresenta coeficiente Beta positivo de 9.98, em 2016, 1,76. Já em 2012, o resultado não é significativo. Por se tratar de população e não amostra, a significância estatística é menos relevante do que o coeficiente. Em 2012, a Comunicação Digital reduziu a Competição (-830.14). Já em 2008 (+9.98) e $2016(+19.73)$, quanto mais acesso à comunicação digital, maior a competição entre os candidatos a prefeito. Desta forma, não há um resultado linear para os três anos estudados, ou uma tendência de aumento ou diminuição dos indicadores durante este período analisado.

\section{Conclusão}

O objetivo deste artigo foi apresentar uma proposta de medição da participação e competição nas eleições brasileiras, utilizando os componentes que integram o Índice de Democratização (ID) de Tatu Vanhanen. Foram testados os efeitos de duas variáveis de comunicação - eletrônica e digital - para a democracia eleitoral, utilizando o Índice de Democratização proposto por Vanhanen aplicados aos municípios brasileiros.

O trabalho compara os resultados das eleições para prefeitos de 2008, 2012 e 2016, em nível agregado - considerando dados de todos os 5,6 mil municípios brasileiros. Os dados levantados tornaram possível esse objetivo, levando ao resultado em relação às hipóteses de pesquisa:

Hipótese principal 1) com a mudança nos espaços de comunicação eleitoral, houve redução da participação e da competição eleitoral, ou seja, redução na democracia eleitoral, no período estudado. Foi parcialmente confirmada. Concluise que os municípios com mais comunicação eleitoral em função da estrutura comunicacional tendem a ter mais democracia eleitoral no indicador de competição, porém menor em participação.

Hipótese secundária 2) Quanto mais estrutura de comunicação tradicional e digital, maior a associação entre as variáveis comunicacionais e o Índice de Democratização. Com os dados de 2008, 2012 e 2016, esta hipótese foi confirmada parcialmente, pois quanto maior a estrutura, menor a participação, com impacto maior da comunicação digital. Porém, há associação com aumento de competição, também com impacto maior da comunicação digital. 
Não é possível afirmar que as mudanças na legislação eleitoral em 2015 quanto à propaganda dos candidatos provocaram modificações significativas na participação, apesar de indicar que, nos municípios onde os eleitores recebem mais informação de seus candidatos (as) a prefeito, a tendência é de uma participação menor. Já para a competição, associada à comunicação digital, há aumento em municípios com mais disponibilidade de acesso à comunicação eleitoral.

Levando em consideração que a maior restrição de espaço da comunicação tradicional se deu em 2015, seria esperada uma diferença de comportamento do ID e indicadores de Participação e Competição entre 2008 e 2012 por um lado e 2016 por outro, com diminuição do ID para 2016. Os testes de regressão mostraram que a Comunicação Digital aparece como significativa pela primeira vez em 2016 $\left(10.93^{* * *}\right)$ para explicar o ID geral, em uma eleição na qual a legislação eleitoral fortaleceu os espaços digitais de comunicação dos candidatos (as).

$\mathrm{Na}$ divisão dos indicadores, 2012 tem um comportamento diferente dos demais anos. A Comunicação digital não é significativa na relação com o Indicador de Participação em 2012 e a Comunicação Tradicional também não agrega no Indicador de Competição em 2012. Percebe-se que a Comunicação Digital passa a ter força a partir de 2016 (10.93), mesmo que o uso das redes digitais seja permitido em campanhas desde 2010.

A proposta de Vanhanen é relevante porque cria um índice a partir de discussões teóricas consolidadas a respeito dos indicadores eleitorais da democracia, principalmente os formulados por Dahl. Ele não se propõe a medir a democracia em si, mas sim a eleitoral, que gera um processo de fortalecimento da democracia como um todo.

A associação entre dados eleitorais e comunicacionais permite analisar a democracia eleitoral para além das instituições e perceber no que resultam as regras estabelecidas e as estruturas de comunicação nos mais diversos municípios. O resultado indica a necessidade de uma outra discussão, mais profunda, sobre os indicadores de competição e participação no Brasil. Mesmo com as diferenças entre cidades, os canais digitais estão aumentando a competição das candidaturas, dando possibilidade de que os candidatos (as) alcancem um número maior de eleitores, o que ajuda na divulgação das informações e, em consequência, acirra a concorrência e fortalece a democracia eleitoral.

Por outro lado, a participação nas eleições, mesmo com o voto obrigatório no Brasil, diminuiu nas eleições analisadas. Não é possível concluir com os dados analisados que a responsabilidade seja da estrutura comunicacional. Porém, chama a atenção o fato de que quanto maior a estrutura de comunicação do município, menor a participação, com impacto maior da comunicação digital. Ou seja, se isolado apenas o aspecto comunicacional, o aumento da possibilidade de comunicação eleitoral por meio digital vem reduzindo um dos indicadores de democratização, que é a participação. 
Diante dos dados e testes realizados, conclui-se que, para o caso dos municípios brasileiros nos anos estudados de eleições majoritárias locais, mais estrutura de comunicação não gera, necessariamente, mais democracia. Os indicadores separados explicam mais o comportamento do que o Índice de Democratização agregado. Não adianta ter mais competição, no caso dos municípios brasileiros, se a participação nas eleições diminui, a democracia eleitoral se enfraquece. Neste sentido, a visão otimista sobre a comunicação digital nas eleições, que levaria a uma democratização, ao menos para as cidades brasileiras, não é confirmada.

\title{
Changes in electoral adVertising AND THE EFFeCtS ON COMPETITION AND PARTICIPATION IN BRAZILIAN LOCAL ELECTIONS BETWEEN 2008 AND 2016
}

\begin{abstract}
This paper presents a proposal for measuring the participation and competition in Brazilian local elections, using the Tatu Vanhanen's Democratization Index, for whom competition and participation are fundamental to analyze democracy in an election. Aggregated data on results of Brazilian local elections between 2008 and 2016 are used in association with the traditional (radio/TV) and digital communication structure in the cities. The hypothesis is that there is an association between intensity of communication and electoral participation. The objective is to analyze how the structure of communication of the electoral advertising affects the participation and competition of the elections, in a time in which there were changes in the electoral laws and a decrease in the traditional communication space. The question guiding the work is: does the visibility of elections caused by changes in electoral rules decrease electoral democracy in these cities? The results show that there are effects in opposite directions.
\end{abstract}

KEYWORDS: Electoral democracy. Local election. Political communication. Electoral advertising.

\section{Cambios EN LA PROPAGANDA ELECTORAL Y EFECTOS EN LA COMPETENCIA Y PARTICIPACIÓN EN LAS ELECCIONES MUNICIPALES BRASILEÑAS ENTRE 2008 Y 2016}

RESUMEN: Este trabajo presenta una propuesta para medir la participación y la competencia en las elecciones brasileñas, utilizando el Índice de Democratización de Tatu Vanhanen, para el cual la competencia y la participación son fundamentales 
para analizar la democracia en una elección. Se utilizan datos agregados de los resultados electorales en los municipios brasileños entre los años 2008 y 2016, asociados a la estructura de la comunicación tradicional (radio y TV) y digital en las ciudades. La hipótesis es que existe una asociación entre la intensidad de la comunicación y la participación electoral. El objetivo es analizar si la mayor o menor estructura comunicativa de la propaganda electoral afecta a la participación y competencia de las elecciones, en un periodo en el que se produjeron cambios en las leyes electorales y una disminución del espacio de comunicación tradicional. La pregunta que guía el trabajo es: ¿la visibilidad de las elecciones provocada con los cambios en las reglas electorales disminuye la democracia electoral en estos municipios? Los resultados muestran que hay efectos en direcciones opuestas.

PALABRAS CLAVE: Democracia electoral. Elecciones locales. Comunicación politica. Propaganda electoral.

\section{REFERÊNCIAS}

ALTMAN, D. \& PÉREZ-LIÑÁN, A. Assessing the Quality of Democracy: Freedom, Competitiveness and Participation in Eighteen Latin American Countries, Democratization, 9:2, 85-100, 2002.

BRASIL. Lei 13.488 de 6 de Outubro de 2017. Altera as Leis n ${ }^{\circ} 9.504$, de 30 de setembro de 1997 (Lei das Eleições), 9.096, de 19 de setembro de 1995, e 4.737, de 15 de julho de 1965 (Código Eleitoral), e revoga dispositivos da Lei no 13.165, de 29 de setembro de 2015 (Minirreforma Eleitoral de 2015), com o fim de promover reforma no ordenamento políticoeleitoral. Disponível em http://www.planalto.gov.br/ccivil_03/_Ato2015-2018/2017/Lei/ L13488.htm. Acessado em 22 de janeiro de 2020.

BRASIL. Presidência da República. Secretaria de Comunicação Social. Pesquisa brasileira de mídia 2016. Brasília: Secom, 2016. Disponível em: http://www.secom.gov.br/atuacao/ pesquisa/lista-de-pesquisas-quantitativas-e-qualitativas-de-contratos-atuais/pesquisabrasileira-de-midia-pbm-2016.pdf/view. Acessado em 17/03/2019.

BRASIL. Lei 13.165 de 29 de Setembro de 2015. Altera as Leis $n^{\circ} 9.504$, de 30 de setembro de 1997, 9.096, de 19 de setembro de 1995, e 4.737, de 15 de julho de 1965 - Código Eleitoral, para reduzir os custos das campanhas eleitorais, simplificar a administração dos Partidos Políticos e incentivar a participação feminina. Disponível em http://www.planalto. gov.br/ccivil_03/_ato2015-2018/2015/lei/113165.htm. Acesso em: 22 jan. 2020.

BRASIL. Lei 12.891 de 11 de dezembro de 2013. Altera as Leis nos 4.737, de 15 de julho de 1965, 9.096, de 19 de setembro de 1995, e 9.504, de 30 de setembro de 1997, para diminuir 


\section{Mudanças da propaganda eleitoral e efeitos na competição e participação em eleições municipais brasileiras entre 2008 e 2016}

o custo das campanhas eleitorais, e revoga dispositivos das Leis nos 4.737, de 15 de julho de 1965, e 9.504, de 30 de setembro de 1997. Disponível em https://presrepublica.jusbrasil. com.br/legislacao/112224421/lei-12891-13. Acesso em: 22 jan. 2020.

BRASIL. Lei 12.034 de 29 de Setembro de 2009. Altera as Leis nos 9.096, de 19 de setembro de 1995 - Lei dos Partidos Políticos, 9.504, de 30 de setembro de 1997, que estabelece normas para as eleições, e 4.737, de 15 de julho de 1965 - Código Eleitoral. Acesso em: 22 jan. 2020.

BRASIL. Lei 11.300 de 10 de Maio de 2006. Dispõe sobre propaganda, financiamento e prestação de contas das despesas com campanhas eleitorais, alterando a Lei $\mathrm{n}^{\circ}$ 9.504, de 30 de setembro de 1997. Disponível em http://www.planalto.gov.br/ccivil_03/_Ato20042006/2006/Lei/L11300.htm. Acesso em: 22 jan. 2020.

BRASIL. Lei 9.504 de 30 de setembro de 1997. Estabelece normas para as eleições. Disponível em http://www.planalto.gov.br/ccivil_03/leis/19504.htm. Acesso em: 22 jan. 2020.

BRASIL. Lei 9100 de 29 de Setembro de 1995. Estabelece normas para a realização das eleições municipais de 3 de outubro de 1996, e dá outras providências. Disponível em https:// presrepublica.jusbrasil.com.br/legislacao/111051/lei-9100-95. Acesso em: 22 jan. 2020.

BRASIL. Lei 8214 de 24 de Julho de 1991. Estabelece normas para a realização das eleições municipais de 3 de outubro de 1992 e dá outras providências. Disponível em http://www. planalto.gov.br/ccivil_03/leis/18214.htm Acesso em: 22 jan. 2020.

CAMPELLO, Cristiane Cavalcanti Barreto. A Propaganda Eleitoral Antecipada após a Lei 13.165/2015 e a Ferramenta de Impulsionamento de publicações nas Redes Sociais, in Revistas de Estudos eleitorais, No 1, Recife: TRE-PE, 2017

CERVI, Emerson Urizzi, Eleições municipais e crise nacional: disputas eleitorais para prefeito e vereador no Brasil em 2016. Anais, $4^{\circ}$ Congreso Latinoamericano y Caribeño de Ciencias Sociales. Salamanca. 17 al 19 de Julio de 2017

Manual de Métodos Quantitativos para Iniciantes em Ciência Política Volume II. Curitiba:CPOP, 2019.

CERVI, Emerson Urizzi; NEVES, Daniela S. Estrutura de comunicação e democratização eleitoral em disputas para prefeito no brasil em 2008 e 2016. Anais. XI Encontro ABCP. Curitiba, 2018.

COPPEDGE, Michael, GERRING, John, ALTMAN, David; BERNHARD, Michael; FISH, Steven; HICKEN, Allen; KROENIG, Matthew; LINDBERG, Staffan I.; MCMANN Kelly; PAXTON, Pamela; SEMETKO, Holli A.; SKAANING Svend-Erik; STATON, Jeffrey; TEORELL, Jan. Conceptualizing and Measuring Democracy: A New Approach. Perspectives on Politics, 9(2), 247-267, 2011. Published online by Cambridge University Press: 03 June 2011. 
DAHL, Robert A. Sobre a Democracia. Brasília: Editora Universidade de Brasília, 2001, 2009.

Poliarquia: participação e oposição. $1^{\mathrm{a}}$ edição. São Paulo: Editora Universidade de São Paulo, 2005.

DIAMOND, Larry, $\mathbf{O}$ espírito da democracia: a luta pela construção de sociedades livres em todo o mundo. Curitiba: Instituto Atuação, 2015.

LIJPHART, Arend. Modelos de Democracia - Formas de Gobierno y resultados em treinta y seis países. Barcelona: Editora Ariel, 2000.

Thinking about Democracy: Power Sharing and Majority Rule in Theory and Practice. London and New York: Routledge, 2007.

NEVES, Daniela; SANTOS, Sandra Avi. Propaganda de rua, televisão e internet: governança eleitoral e o impacto para a comunicação política brasileira. In: Anais. Noveno Congresso Latinoamericano de Ciência Política, 2017, Montevidéu. Anais Democracia en Racession. Montevidéu: Alacip, 2017.

NORRIS, Pipa. Why Elections Fail. New York: Cambridge University Press, 2015.

O'DONELL, Guilhermo. Ilusions about consolidation.In In PLATTNER, Marc F., and DIAMOND, Larry Jay. The Global Divergence of Democracies. Baltimore: Johns Hopkins University Press, 2001.

PIERANTI, Octavio Penna, A distribuição geográfica das estações locais de TV no Brasil, in Revista Famecos (Online). Porto Alegre, v. 25, n. 3, setembro, outubro, novembro e dezembro de 2018.

PRZEWORSKI, Adam, ALVARES, Michael E., CHEIBUB, José Antonio e FIGUEIREDO Fernando Limongi What Makes Democracies Endure? In PLATTNER, Marc F., and DIAMOND, Larry Jay. The Global Divergence of Democracies. Baltimore: Johns Hopkins University Press, 2001.

SCHUDSON, Michael. Why democracies need an unlovable press. Polity, 2008.

VANHANEN, Tatu Democratization: A Comparative Analysis of 170 Countries. London: Routledge, 2003.

A New Dataset for Measuring Democracy, 1810-1998, Journal of Peace Research, vol. 37, no. 2, 2000, pp. 251-265 Sage Publications (London, Thousand Oaks, CA and New Delhi), 2000.

Prospects of democracy: A study of 172 countries. London and New

York: Routledge. (1997). 
Mudanças da propaganda eleitoral e efeitos na competição e participação em eleiçôes municipais brasileiras entre 2008 e 2016

The process of Democratization: A comparative study of 147

States - 1980-88. New York: Taylor \& France New York Inc. 1990

The Level of Democratization Related to Socioeconomic Variables in 147 States in 198-85, Scandinavian Political Studies, Vd. 12 - No. 2. 1989

The Emergence of Democracy: A Comparative Study of 119 States, 1850-1979, Commentationes Scientiarum Socialum 24. Helsinki: The Finish Society of Science and Letters. 1984

Dependence of Power on Resources: A Comparative Study of 114 States in the 1960s. Department of Social Sciences Publications. Nº 11. Jyväskylä: University of Jyväskylä, 1971.

Recebido em 18/11/2020.

Aprovado em 23/03/2021. 


\section{ANEXOS}

Anexo 1 - Temas de propaganda e quando entraram ou foram proibidas:

Ação permitida

Ação proibida

Com restrições

Não citado na legislação

\begin{tabular}{|c|c|c|c|c|c|c|c|c|}
\hline TIPOS DEPROPAGANDA & $\begin{array}{c}1991 \\
\text { Lei } \\
8.214\end{array}$ & $\begin{array}{c}1995 \\
\text { Lei } \\
9.100\end{array}$ & $\begin{array}{c}1997 \\
\text { Lei } \\
9.504\end{array}$ & $\begin{array}{c}2006 \\
\text { Lei } \\
11300\end{array}$ & $\begin{array}{c}2009 \\
\text { Lei } \\
12034\end{array}$ & $\begin{array}{c}2013 \\
\text { Lei } \\
12891\end{array}$ & $\begin{array}{c}2015 \\
\text { Lei } \\
13165\end{array}$ & $\begin{array}{c}2017 \\
\text { Lei } \\
13488\end{array}$ \\
\hline \multicolumn{9}{|l|}{ Propaganda em imprensa escrita } \\
\hline \multicolumn{9}{|l|}{$\begin{array}{l}\text { Propaganda em bens que dependam de concessão do } \\
\text { Poder Público }\end{array}$} \\
\hline \multicolumn{9}{|l|}{$\begin{array}{l}\text { Propaganda em locais públicos indicados pela } \\
\text { prefeitura }\end{array}$} \\
\hline \multicolumn{9}{|l|}{ Propaganda em bens particulares } \\
\hline \multicolumn{9}{|l|}{ Distribuição de folhetos, volantes e demais impressos } \\
\hline \multicolumn{9}{|l|}{ Outdoors } \\
\hline \multicolumn{9}{|l|}{$\begin{array}{l}\text { Anúncios luminosos, faixas, cartazes colocados em } \\
\text { vias públicas, inclusive rodovias }\end{array}$} \\
\hline \multicolumn{9}{|l|}{$\begin{array}{l}\text { Projeção de vídeo, cartazes fixados em locais com } \\
\text { aglomeração (como cinemas e restaurantes) }\end{array}$} \\
\hline \multicolumn{9}{|l|}{$\begin{array}{l}\text { Utilização de faixas ou cartazes em ginásios e estádios } \\
\text { desportivos. }\end{array}$} \\
\hline \multicolumn{9}{|l|}{$\begin{array}{l}\text { Circuito fechado de som ou de imagem em recintos a } \\
\text { que o público tenha acesso. }\end{array}$} \\
\hline \multicolumn{9}{|l|}{ Ofender candidato } \\
\hline \multicolumn{9}{|l|}{$\begin{array}{l}\text { Distribuição de camisetas, chaveiros e outros brindes } \\
\text { de campanha }\end{array}$} \\
\hline \multicolumn{9}{|l|}{ Realização de comícios } \\
\hline \multicolumn{9}{|l|}{ Carro de som } \\
\hline \multicolumn{9}{|l|}{ Debates em emissoras de rádio e televisão } \\
\hline \multicolumn{9}{|l|}{ Propaganda de Boca de Urna no dia da eleição } \\
\hline \multicolumn{9}{|l|}{ Cenas externas no horário eleitoral } \\
\hline \multicolumn{9}{|l|}{ Propaganda em veículos } \\
\hline \multicolumn{9}{|l|}{ Cavaletes, bonecos, placas, estandartes, faixas } \\
\hline \multicolumn{9}{|l|}{ Mesa de distribuição de material na rua } \\
\hline \multicolumn{9}{|l|}{$\begin{array}{l}\text { Placas, estandartes, faixas em postes de iluminação } \\
\text { pública, viadutos, passarelas e pontes }\end{array}$} \\
\hline \multicolumn{9}{|l|}{$\begin{array}{l}\text { Inserções no rádio e na TV usando montagens, } \\
\text { computaçãa gráfica e efeitos especiais }\end{array}$} \\
\hline \multicolumn{9}{|l|}{$\begin{array}{l}\text { Propaganda que possa degradar ou ridicularizar } \\
\text { candidatos (as) }\end{array}$} \\
\hline \multicolumn{9}{|l|}{ Showmício com artistas remunerados ou não. } \\
\hline \multicolumn{9}{|l|}{ Trios elétricos } \\
\hline \multicolumn{9}{|l|}{ Propaganda antecipada } \\
\hline \multicolumn{9}{|l|}{ Propaganda por meio de mensagem eletrônica } \\
\hline \multicolumn{9}{|l|}{ Propaganda por meio de blogs, redes sociais } \\
\hline \multicolumn{9}{|l|}{ Propaganda paga na internet } \\
\hline Impulsionamento de conteúdo nas redes sociais. & & & & & & & & \\
\hline
\end{tabular}

Fonte: os autores, com auxílio infográfico de Matias Peruyera. 


\section{ANEXO 2}

\section{O QUE DIZEM AS LEIS ELEITORAIS SOBRE USO DA INTERNET NAS CAMPANHAS}

\begin{tabular}{|c|c|}
\hline $\begin{array}{l}\text { Ano } 2006 \text { - } \\
\text { Lei } 11.300\end{array}$ & Prestação de contas pela internet \\
\hline $\begin{array}{l}\text { Ano } 2009 \text { - } \\
\text { Lei } 12.034\end{array}$ & $\begin{array}{l}\text { - Doações pela internet } \\
\text { - Site de candidato, partido ou coligação } \\
\text { - Propaganda por meio de mensagem eletrônica para endereços cadastrados } \\
\text { gratuitamente pelo candidato, partido ou coligação; } \\
\text { - Propaganda por meio de blogs, redes sociais, sítios de mensagens instantâneas } \\
\text { e assemelhados. } \\
\text { - Participação de filiados a partidos ou de pré-candidatos (as) em entrevistas, } \\
\text { programas, encontros ou debates na internet } \\
\text { - Na internet, vedada qualquer tipo de propaganda paga. } \\
\text { - É livre a manifestação do pensamento, vedado o anonimato durante a campanha } \\
\text { eleitoral, por meio da internet, assegurado o direito de resposta. } \\
\text { - Direito de resposta: no mesmo veículo, espaço, local, horário, página eletrônica, } \\
\text { tamanho, caracteres usados na ofensa, em até } 48 \text { horas após a entrega com a } \\
\text { resposta do ofendido } \\
\text { - É proibida a venda de cadastro de endereços eletrônicos }\end{array}$ \\
\hline $\begin{array}{l}\text { Ano } 2013 \text { - } \\
\text { Lei } 12.891\end{array}$ & $\begin{array}{l}\text { - Retirada de conteúdo ofensivo. } \\
\text { - Constitui crime a contratação direta ou indireta de grupo de pessoas com a } \\
\text { finalidade específica de emitir mensagens ou comentários na internet para ofender } \\
\text { a honra ou denegrir a imagem de candidato, partido ou coligação. }\end{array}$ \\
\hline $\begin{array}{l}\text { Ano } 2015 \text { - } \\
\text { Lei } 13.165\end{array}$ & $\begin{array}{l}\text { - Não configura propaganda antecipada na internet: menção à pretensa } \\
\text { candidatura, exaltação de qualidades pessoais dos pré-candidatos (as), desde que } \\
\text { não haja pedido explícito de voto. } \\
\text { - Direito de resposta: a qualquer tempo, quando se tratar de conteúdo que esteja } \\
\text { sendo divulgado na internet, ou em } 72 \text { horas, após a sua retirada. }\end{array}$ \\
\hline $\begin{array}{c}\text { Ano } 2017 \text { - } \\
\text { Lei } 13.488\end{array}$ & $\begin{array}{l}\text { - Propaganda pela internet por meio de blogs, redes sociais, sítios de mensagens } \\
\text { instantâneas e aplicações de internet assemelhadas cujo conteúdo seja gerado ou } \\
\text { editado por: a) candidatos (as), partidos ou coligações; ou b) qualquer pessoa } \\
\text { natural, desde que não contrate impulsionamento de conteúdos. } \\
\text { - É vedada a veiculação de qualquer tipo de propaganda eleitoral paga na internet, } \\
\text { excetuado o impulsionamento de conteúdos, desde que identificado de forma } \\
\text { inequívoca como tal e contratado exclusivamente por partidos, coligações e } \\
\text { candidatos (as) e seus representantes. } \\
\text { - É vedada a utilização de impulsionamento de conteúdos e ferramentas digitais } \\
\text { não disponibilizadas pelo provedor da aplicação de internet, ainda que gratuitas, } \\
\text { para alterar o teor ou a repercussão de propaganda eleitoral, tanto próprios quanto } \\
\text { de terceiros. }\end{array}$ \\
\hline
\end{tabular}

Fonte: Leis eleitorais. 